\title{
Robust Hybrid Optimization Method to Reduce Investment Portfolio Risk using Fusion of Modern Portfolio Theory and Genetic Algorithm
}

\author{
Nashirah Abu Bakar, Sofian Rosbi
}

\begin{abstract}
Main objective of this study is to develop hybrid optimization method for reducing investment portfolio risk. The methods selected in this study are the combination of Modern Portfolio Theory (MPT) and genetic algorithm optimization approach. Three stocks from Malaysian Stock Exchange are selected in developing the investment portfolio namely Malayan Banking Berhad, Hap Seng Consolidated Berhad and Top Glove Corporation Berhad. Result indicates the modern portfolio theory can give optimal portfolio weightage with maximum return for tolerate level of investment risk. In addition, genetic algorithm enhanced the optimal searching method to find global minimum of investment risk. Result shows the minimum portfolio risk in objective function is 2.122118 with implementation genetic algorithm optimization. The optimal combination of portfolio investment is $32.24 \%$ in asset $A$ (Malayan Banking Berhad), $52.37 \%$ in asset B (Hap Seng Consolidated Berhad), and $15.30 \%$ in asset $C$ (Top Gove Corporation Berhad). The important of this study is it will assist investor in making better decision to optimize their return for given level of investment risk. Furthermore, this hybrid method provides a better accuracy of prediction for return of investment and portfolio risk.
\end{abstract}

Index Terms: Investment, Portfolio Risk, Modern Portfolio Theory, Genetic Algorithm.

\section{INTRODUCTION}

Portfolio selection is one of the most important research fields in the investment decision-making. Investors that have good information can manage their portfolio investment effectively by select a good combination of investments portfolio. In 1952, Modern Portfolio Theory was introduced by Harry Markowitz in order to analyze the optimal return for portfolio investment. This theory explained how investors can optimal investment and a consumption decision of an individual who has available in two investment instruments [1]. Modern Portfolio Theory indicate that the portfolio risk can be reduced by diversification approach for different assets [2] and also indicated that investment portfolio can attain low risk by combination of several stocks [3]. Study that examined the volatility of sharia-compliant companies listed on the Malaysian Stock Exchange found that the mean

Revised Manuscript Received on September 22, 2019.

Nashirah Abu Bakar, Islamic Business School, College of Business, Universiti Utara Malaysia, Kedah, Malaysia.

Sofian Rosbi, School of Mechatronic Engineering, Universiti Malaysia Perlis, Arau, Malaysia. value for volatility rate is $4.85 \%$ and standard deviation is $2.23 \%$. Result from Shapiro-Wilk normality test indicates data distribution for average monthly return and volatility follow normal data distribution [4].

Traditionally, most of the investment are followed Theory of Investment that stated it was enough looking into one stock only [5]. Therefore, most of current study used Modern Portfolio Theory for problem solving in investment portfolio selection [6]-[9]. After Markowitz's work, researchers have shown great enthusiasm in portfolio management, trying different mathematical approaches to develop the theory of portfolio selection [10], [11]. Study that examine the volatility rate of sharia-compliant company listed on the Malaysian Stock Exchange using Monte Carlo Simulation method found that Monte Carlo Simulation proved the volatility rate is $4.85 \%$ and standard deviation is 2.23 [12]. The result shows the value of volatility rate is under statistical control with implementation of Monte Carlo Simulation approach [12]. Monte Carlo simulations are a very powerful way to demonstrate the basic sampling properties of various statistics in econometrics [13].

Currently, the increased availability of computing power was developed a new technique of computation and optimization. Evolutionary Computation is well-known for producing the solutions in optimization problems [14]. Computational capacity and the widespread availability of computers have enabled development of a new generation of intelligent computing techniques such as expert systems, fuzzy logic, neural networks and genetic algorithms [10]. These methods are used to find a solution for optimization problems in varies field such as physics, engineering and technology and logistic [15]-[22]. Even there are many studies used Genetic Algorithm approach, but study that implements this method in the financial field is still lack of investigation. Therefore, it is important to investigate the performance of companies listed on the Malaysian Stock Exchange using combination of Modern Portfolio Theory and Genetic Algorithm optimization approach in order to find optimal value for portfolio investment selection. The function of this methods is to select investment portfolio that have optimal weighted to maximize a return at tolerate risk level. In another term, this study tries to select optimal portfolio to reduce risk at certain expected return. Moreover, managing a risk in investment portfolio is very important part in order to maintain the financial health of an 
investment portfolio selection.

Genetic Algorithm is one of the numerical and optimization methods in problem-solving decision. In developing portfolio risk analysis, small number of assets can be solved using a traditional technique. However, with the increments of assets in portfolio, the complexity to find optimal solution also increases. Therefore, a Genetic Algorithm method was used in this study to find solutions for problems unsolvable by traditional methods [10].

Thus, this paper developed Modern Portfolio Theory compliment with integration of genetic algorithm method to solve the problem in selecting optimal portfolio investment in order to reduce risk at certain expected return for companies listed on the Malaysia Stock Exchange. The companies used in this study are three assets namely Malayan Banking Berhad, Hap Seng Consolidated Berhad and Top Glove Corporation Berhad.

\section{LITERATURE REVIEW}

A prediction method is one of the most important methods in the investment field. It must consider several things in order to maximize a return and minimize a risk. Firstly, stock market price is fluctuated that is every minute the price was changed. Secondly, there are many companies in the stock market that need a good technique to monitor. Therefore, various methods were developed in order to analyze the performance of stock price such as ARIMA model, Monte Carlo, Modern Portfolio Theory and Genetic Algorithm [23], [24]. Even there are many methods in forecasting area but it is still lack of researches implement computational and optimization using intelligent computing techniques implement in the financial area. Therefore, this study try to focus two methods that are Modern Portfolio Theory and Genetic Algorithm approach in order to analysis the optimal value for investment portfolio selection.

Genetic Algorithm provides a well-developed paradigm to form a portfolio with the maximum expected return at a given level of risk tolerance. Genetic Algorithm is one of the most famous techniques in optimization solutions and developed by Holland in 1975. Study regarding genetic algorithm applied in Madrid Stock Market suggest that, for reasonable trading costs, the technical trading rule is always superior to a risk-adjusted buy-and-hold strategy [22]. The other study proved that Genetic Algorithm is more conservative as compared to those computed using Monte Carlo simulation [25].

Modern Portfolio Theory is a technique of selection a portfolio that minimizes risk for a given level of reward, where reward is the mean of the portfolio return distribution and risk is measured as the variance of the portfolio return distribution [10]. This theory also explains the expected return that investors desired to earn at the same time can reduced a risk in the portfolio selection. The risk component of modern portfolio theory can be measured, using various mathematical formulations, and reduced via the concept of diversification which aims to properly select a weighted collection of investment assets that together exhibit lower risk factors than investment in any individual asset or singular asset class [26]. A well-diversified portfolio contains of different types of securities from different industries, with varying level of risk. Thus, it is important to diversify the investment portfolio. Study regarding modern portfolio theory and risk based on incremental entropy found the new theory emphasizes that there is an objectively optimal portfolio for given probability of returns [27]. While, study that analyze the benefits of modern portfolio theory found that the standard geographic and sector diversification allow for a good results and more efficient portfolios [28].

Study regarding the behavior of share price companies listed on the Malaysian Stock Exchange found that the data was follow normality of data [29]. Therefore, the main focus of this study is to develop hybrid optimization method for reducing investment portfolio risk. The methods selected in this study are the combination of Modern Portfolio Theory and genetic algorithm optimization approach.

\section{RESEARCH METHODOLOGY}

Main purpose of this research is to develop robust method in determine lower investment risk. Therefore, this study calculated portfolio risk using Modern Portfolio Theory. Then, this study applied genetic algorithm optimization to search for optimal global solution in reducing risk.

\section{A. Data selection process}

This study selected three stocks prices in developing investment portfolio. The three stocks are Malayan Banking Berhad, Hap Seng Consolidated Berhad and Top Glove Corporation Berhad. This study collected daily stock prices from Thomson Reuters Datastream. Firstly, this study calculated return rate of stock prices using Equation (1).

$R_{i, t}=\left(\frac{P_{t}-P_{t-1}}{P_{t-1}}\right) \times 100 \%$

In Equation (1), the parameters are defined as follow:

$R_{i, t}$ is return for asset $i$, at observation period $t$,

$P_{t}$ is stock price of asset $i$, at observation period $t$, and

$P_{t-1}$ is stock price of asset $i$, at observation period $t-1$.

Next, this research performed normal distribution checking for return rate for each of stock prices. The probability density of normal distribution of return data is represented using Equation (2).

$$
f\left(x \mid \mu, \sigma^{2}\right)=\frac{1}{\sqrt{2 \pi \sigma^{2}}} e^{-\frac{(x-\mu)^{2}}{2 \sigma^{2}}}
$$

In Equation (2), the parameters are explained as below: $\mu$ : Mean or expectation of distribution for random variable. $\sigma:$ Standard deviation of data.

\section{$\sigma^{2}$ : Variance for data distribution.}

This project implemented Shapiro-Wilk statistical test to prove normality of data distribution for return of stock prices. The Shapiro-Wilk Test is more appropriate for small sample 
sizes ( $<50$ samples), but can also handle sample sizes as large as 2000.

The Shapiro-Wilk normality test is developed with null hypothesis is considered that a sample $x_{1}, x_{2}, x_{3}, \ldots, x_{n}$ distributed according to normally distribution population. The W-statistics for Shapiro Wilk normality test is defined in Equation (3)

$W=\frac{\left(\sum_{i=1}^{n} a_{i} x_{(i)}\right)^{2}}{\sum_{i=1}^{n}\left(x_{i}-\bar{x}\right)^{2}}$

In Equation (3), the parameters are described as follows:

$x_{(i)}$ is $i$-th order statistics,

$\bar{x}$ is sample mean,

$a_{i}$ is tabulated coefficient using Equation (4).

$\left(a_{1}, a_{2}, a_{3}, \ldots, a_{n}\right)=\frac{m^{\mathrm{T}} V^{-1}}{C}$

Parameters in Equation (4) are described as follows:

$C$ is vector norm,

$C=\left\|V^{-1} m\right\|=\sqrt{m^{\mathrm{T}} V^{-1} V^{-1} m}$

$m$ is vector that made of the expected values of the order statistics of independent and identically distributed random variables sampled from the standard normal distribution, and $V$ is covariance matrix of normal order statistics.

\section{B. Modern Portfolio Theory for developing investment portfolio}

Modern Portfolio Theory is a mathematical framework for assembling a portfolio of different assets to achieve the expected return is maximized for a given level of risk. In other definition, Modern Portfolio Theory is a theory of finance that attempts to maximize portfolio expected return for a given amount of risk, or minimize risk for given level of expected return.

Modern Portfolio Theory grounded on assumption that investors are risk averse. The definition of risk averse is investors prefer less risk for portfolio that offer the same expected return. Thus, an investor will take on increased risk only if compensated by higher expected returns. Conversely, an investor who wants higher expected returns must accept more risk. The exact trade-off will be the same for all investors, but different investors will evaluate the trade-off differently based on individual risk aversion characteristics. The implication is that a rational investor will not invest in a portfolio if a second portfolio exists with a more favorable risk-expected return profile.

The expected return for portfolio is calculated using Equation (5).

$\mathrm{E}\left(R_{p}\right)=\sum_{i=1}^{n} w_{i} \mathrm{E}\left(R_{i}\right)$
In Equation (1), the parameters are described as below: $R_{p}$ : Return of portfolio consists of different assets.

$R_{i}$ : Return of asset $i$.

$w_{i}$ : Proportion of weightage for asset $i$ in portfolio.

Next, variance of portfolio return is calculated using Equation (6).

$\sigma_{p}^{2}=\sum_{i=1}^{n} w_{i}^{2} \sigma_{i}^{2}+\sum_{i} \sum_{j \neq i} w_{i} w_{j} \sigma_{i} \sigma_{j} \rho_{i j}$

(6)

In Equation (2), the parameters are described as below:

$\sigma_{i}$ : Standard deviation for return of asset $i$.

$w_{i}$ : Weightage proportion for asset $i$ in portfolio.

$\rho_{i j}$ : Pearson correlation coefficient between return of asset $i$ and asset $j$.

In this study, three stocks were selected from Malaysia Stock Exchange in developing diversified investment portfolio. The portfolio return for three assets is described in Equation (7).

$$
\mathrm{E}\left(R_{p}\right)=w_{A} \mathrm{E}\left(R_{A}\right)+w_{B} \mathrm{E}\left(R_{B}\right)+w_{c}\left(R_{C}\right)
$$

Parameters in Equation (7) are described as follows:

$\mathrm{E}\left(R_{p}\right)$ : Expected return for portfolio with three different assets.

$\mathrm{E}\left(R_{A}\right):$ Expected return for asset $\mathrm{A}$.

$\mathrm{E}\left(R_{B}\right):$ Expected return for asset $\mathrm{B}$.

$\mathrm{E}\left(R_{C}\right)$ : Expected return for asset C.

$w_{A}$ : Proportion of weightage for asset $\mathrm{A}$ in portfolio.

$w_{B}$ : Proportion of weightage for asset $\mathrm{B}$ in portfolio.

$w_{C}$ : Proportion of weightage for asset $\mathrm{C}$ in portfolio.

Then, the investment risk for portfolio is measured using standard deviation. The variance for portfolio investment is represented by using Equation (8).

$$
\begin{aligned}
\sigma_{p}^{2}= & w_{A}^{2} \sigma_{A}^{2}+w_{B}^{2} \sigma_{B}^{2}+w_{C}^{2} \sigma_{C}^{2}+2 w_{A} w_{B} \sigma_{A} \sigma_{B} \rho_{A B} \\
& +2 w_{A} w_{C} \sigma_{A} \sigma_{C} \rho_{A C}+2 w_{B} w_{C} \sigma_{B} \sigma_{C} \rho_{B C}
\end{aligned}
$$

Where,

$\sigma_{A}$ is standard deviation of return for asset A,

$\sigma_{B}$ is standard deviation of return for asset B,

$\sigma_{C}$ is standard deviation of return for asset $\mathrm{C}$,

$\rho_{A B}$ is correlation for return rate between asset $\mathrm{A}$ and $\mathrm{B}$,

$\rho_{B C}$ is correlation for return rate between asset $\mathrm{B}$ and $\mathrm{C}$, and $\rho_{A C}$ is correlation for return rate between asset $\mathrm{A}$ and $\mathrm{C}$.

In Equation (8), the Pearson correlation coefficient is derived using next procedure. Consider there are two random variables represents by variable $X$ and $Y$. Pearson correlation coefficient between these two variables is represented by Equation (9).

$$
\rho_{X Y}=\frac{\operatorname{cov}(X, Y)}{\sigma_{X} \sigma_{Y}}
$$


Parameters in Equation (9) are explained as below: $\operatorname{cov}(X, Y)$ is covariance between variable $X$ and $Y$,

$\sigma_{X}$ is standard deviation of $X$ variable, and

$\sigma_{Y}$ is standard deviation of $Y$ variable.

Then, the Pearson correlation coefficient can be interpret using term of mean and expected values.

$\operatorname{cov}(X, Y)=\mathrm{E}\left[\left(X-\mu_{X}\right)\left(Y-\mu_{Y}\right)\right]$

Where,

$\mathrm{E}$ is expectation,

$\mu_{X}$ is mean of variable $X$, and

$\mu_{Y}$ is mean of variable $Y$.

Next, Equation (9) can be re-arranged to become Equation (10).

$\rho_{X, Y}=\frac{\mathrm{E}\left[\left(X-\mu_{X}\right)\left(Y-\mu_{Y}\right)\right]}{\sigma_{X} \sigma_{Y}}$

The coefficient can be expressed in terms of uncentered moments as Equation (11).

$\rho_{X, Y}=\frac{\mathrm{E}[X Y]-\mathrm{E}[X] \mathrm{E}[Y]}{\sqrt{\mathrm{E}\left[X^{2}\right]-[\mathrm{E}[X]]^{2}} \sqrt{\mathrm{E}\left[Y^{2}\right]-[\mathrm{E}[Y]]^{2}}}$

The correlation coefficient for a sample can be derived as Equation (12). Consider the sample has $n$ pair of $x, y$ variables.

$$
\tau_{x y}=\frac{\sum_{i=1}^{n}\left(x_{i}-\bar{x}\right)\left(y_{i}-\bar{y}\right)}{\sqrt{\sum_{i=1}^{n}\left(x_{i}-\bar{x}\right)^{2}} \sqrt{\sum_{i=1}^{n}\left(y_{i}-\bar{y}\right)^{2}}}
$$

Sample mean of $x$ variable, $\bar{x}=\frac{1}{n} \sum_{i=1}^{n} x_{i}$

Sample mean of $y$ variable, $\bar{y}=\frac{1}{n} \sum_{i=1}^{n} y_{i}$

Then, this study re-arranged Equation (12) with considering sample mean.

$$
\begin{gathered}
\tau_{x y}=\frac{n \sum_{i=1}^{n} x_{i} y_{i}-\sum_{i=1}^{n} x_{i} \sum_{i=1}^{n} y_{i}}{\sqrt{n \sum_{i=1}^{n} x_{i}^{2}-\left(\sum_{i=1}^{n} x_{i}\right)^{2}} \sqrt{n \sum_{i=1}^{n} y_{i}^{2}-\left(\sum_{i=1}^{n} y_{i}\right)^{2}}} \\
\tau_{x y}=\frac{\sum_{i=1}^{n} x_{i} y_{i}-n \bar{x} \bar{y}}{\sqrt{\left(\sum_{i=1}^{n} x_{i}^{2}-n \bar{x}^{2}\right)} \sqrt{\left(\sum_{i=1}^{n} y_{i}^{2}-n \bar{y}^{2}\right)}} \ldots \ldots \ldots . .
\end{gathered}
$$

\section{Genetic algorithm for optimization}

The genetic algorithm is a method for solving both constrained and unconstrained optimization problems that is based on natural selection, the process that drives biological evolution. The genetic algorithm repeatedly modifies a population of individual solutions. At each step, the genetic algorithm selects individuals at random from the current population to be parents and uses them to produce the children for the next generation. Over successive generations, the population evolves toward an optimal solution. Genetic algorithm appropriate to solve a variety of optimization problems that are not well suited for standard optimization algorithms, including problems in which the objective function is discontinuous, non-differentiable, stochastic, or highly nonlinear.

The evolution usually starts from a population of randomly generated individuals, and is an iterative process, with the population in every iteration is called a generation. In each generation, the fitness of every individual in the population is evaluated; the fitness is usually the value of the objective function in the optimization problem being solved. The more fit individuals are stochastically selected from the current population, and each individual genome is modified (recombined and possibly randomly mutated) to form a new generation. The new generation of candidate solutions is then used in the next iteration of the algorithm. Commonly, the algorithm terminates when either a maximum number of generations has been produced, or a satisfactory fitness level has been reached for the population.

This study implemented genetic algorithm optimization with integration of Modern Portfolio Theory for portfolio investment. The purpose of this study is to develop portfolio composition with lowest risk of investment. Fig. 1 shows the procedure of genetic algorithm with integration of Modern Portfolio Theory.

This genetic algorithm starts with generating initial solution for minimizing risk of portfolio investment. In this study, the stopping criteria is set as this algorithm will achieve optimal solution if the function tolerance change is less than $1.0 \times 10^{-6}$. If this value is not meet, the algorithm needs to produce new generation of solutions using selection operator, crossover operator and mutation operator in genetic algorithm approach. The new solution needs to evaluate using objective function. If the stopping criterion is achieved, the study achieved global optimum value.

The genetic algorithm uses three types of rules at each step to create the next generation from the current population:

(i) Selection rules select the individuals, called parents that contribute to the population at the next generation.

(ii)Crossover rules combine two parents to form children for the next generation.

(iii)Mutation rules apply random changes to individual parents to form children.

A genetic algorithm differs from a classical, derivative-based, optimization algorithm in two ways:

(i) A genetic algorithm generates a population of points in every iteration process. Meanwhile, a classical algorithm generates a single point at each iteration process.

(ii)A genetic algorithm selects the next population by computation using random 
number generators, whereas a classical algorithm selects the next point by deterministic computation.

Compared to traditional artificial intelligence, a genetic algorithm provides many advantages. It is more robust and is susceptible to breakdowns due to slight changes in inputs or due to the presence of noise. With respect to other optimization methods like praxis, linear programming, heuristic, first or breadth-first, a genetic algorithm can provide better and more significant results while searching large multi-modal state spaces, large state spaces or n-dimensional surfaces.

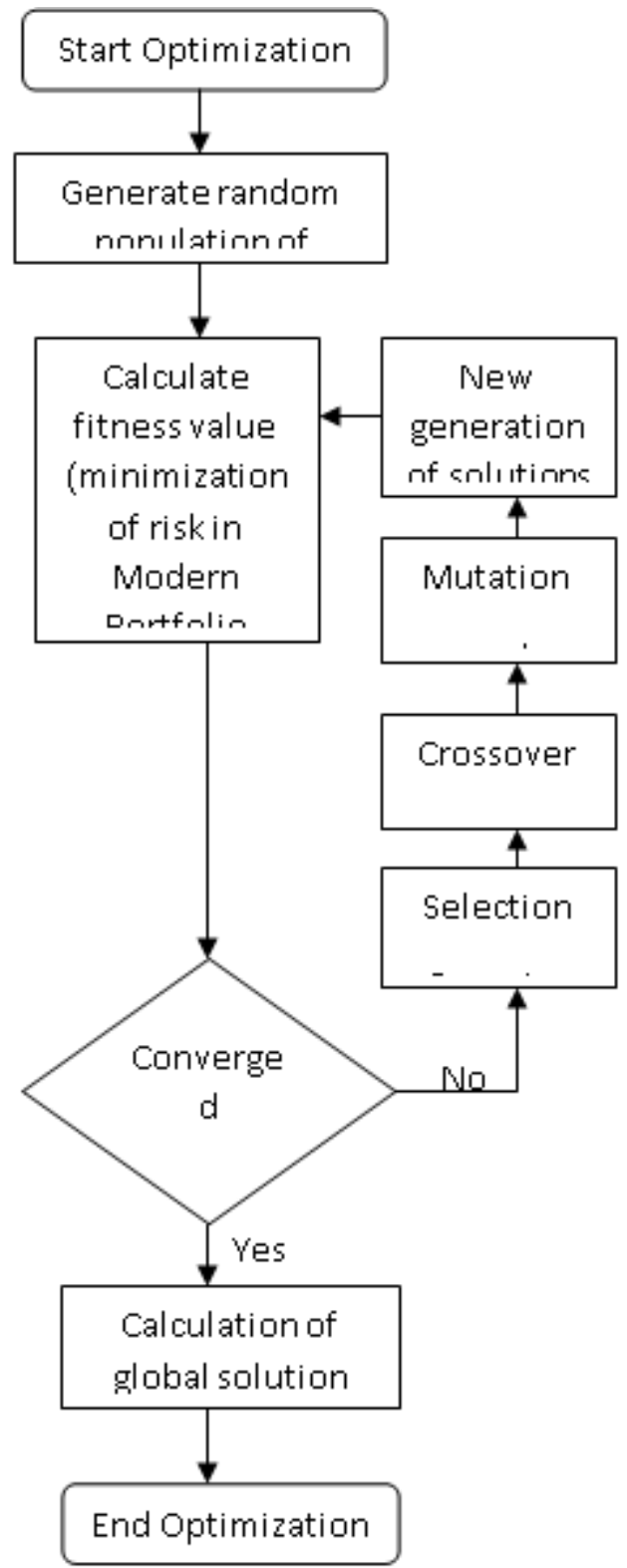

Fig. 1. Genetic algorithm process flow with integration of Modern Portfolio Theory

\section{RESULT AND DISCUSSION}

The objective of this study is to evaluate the portfolio investment using Modern Portfolio Theory and optimization method namely genetic algorithm. Therefore, the methodologies implemented in this study are data selection process, correlation analysis, investment risk analysis and optimization using genetic algorithm.

\section{A. Data selection process}

This study selected three financial assets namely three type of stocks listed in Malaysian Stock Exchange. The stocks are Malayan Banking Berhad, Hap Seng Consolidated Berhad and Top Glove Corporation Berhad. Data are collected from database of Thomson Reuters Datastream. The analysis period is from $1^{\text {st }}$ January 2016 until $31^{\text {st }}$ October 2017. This study calculated the monthly data for analysis procedure. There are 34 monthly observations for evaluating the investment portfolio risk.

\section{i. Malayan Banking stock price analysis}

Next, Fig. 2 shows the dynamic movement of stock price for Malayan Banking Berhad. The maximum value of stock price is MYR 10.58 in April 2018 (28 ${ }^{\text {th }}$ monthly observation). The minimum value of stock price is MYR 7.70 in October 2016 ( $10^{\text {th }}$ monthly observation).

Then, this study calculated the return rate for stock price. Fig. 3 shows return rate for stock of Malayan Banking Berhad. The average of return rate is $0.47 \%$. The standard deviation is $3.34 \%$. Meanwhile, the maximum value of return rate is $6.12 \%$ in March 2017 (15 ${ }^{\text {th }}$ monthly observation). The minimum value of return rate is $-10.48 \%$ in June 2018 ( $30^{\text {th }}$ monthly observation).

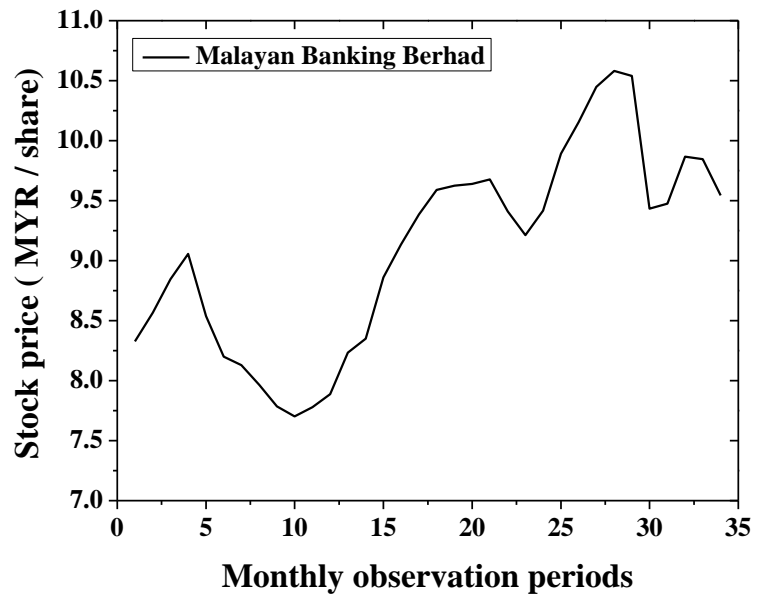

Fig. 2. Dynamic movement of stock price for Malayan Banking Berhad

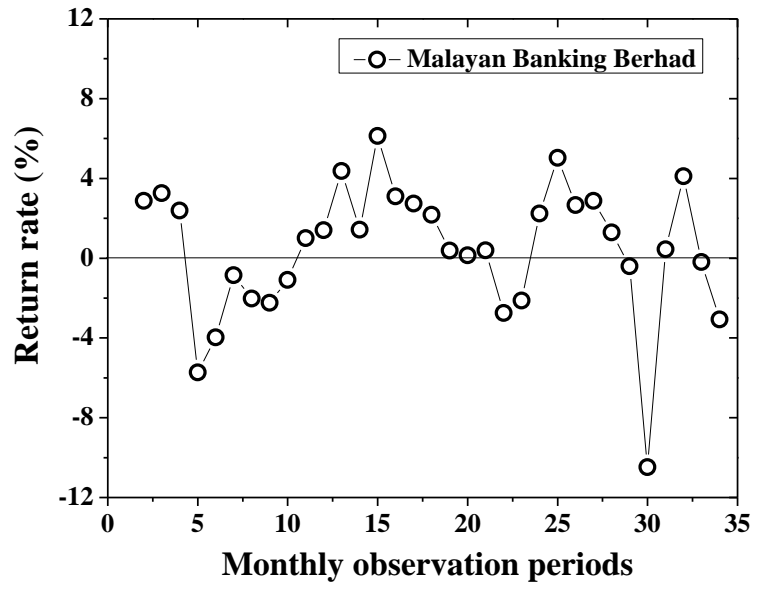

Fig. 3. Return of stock price for Malayan Banking Berhad 
This study performed normality using graphical and numerical statistical test. Fig. 4 shows normality distribution plot of return rate for stock of Malayan Banking Berhad. Graphical plot shows only one data is deviate from normal distribution which is the value of $-10.48 \%$ in $30^{\text {th }}$ monthly observation (June 2018). Therefore, this study concluded the data distribution follows normal distribution although there is one outlier.

Next, this study evaluated normality data distribution using Shapiro Wilk statistical test. Table I exhibits normality test of return data distribution for Malayan Banking Berhad using Shapiro Wilk statistical test. The significant value (p-value) is 0.050 that is less than 0.1 significant levels. Therefore, the significant value concluded return data distribution follows non-normal distribution.

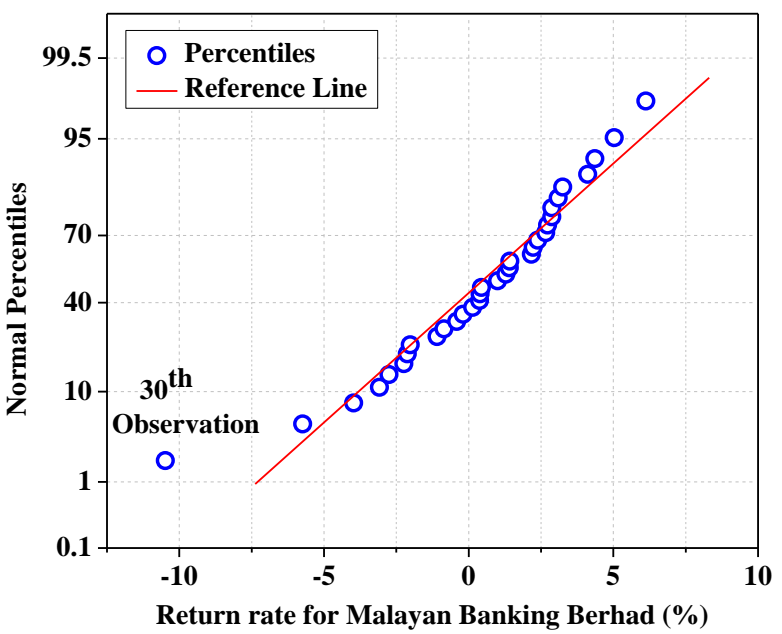

Fig. 4. Normality distribution plot of return rate for Malayan Banking Berhad

Table I. Normality test of return data distribution for Malayan Banking Berhad

\begin{tabular}{|c|c|c|}
\hline \multicolumn{3}{|c|}{ Shapiro Wilk normality test } \\
\hline Statistics & Degree of freedom & Significant value \\
\hline 0.936 & 33 & 0.050 \\
\hline
\end{tabular}

\section{ii. Hap Seng Consolidated Berhad stock price analysis}

This section describes data behavior of stock price for Hap Seng Consolidated Berhad. Fig. 5 shows the dynamic movement of stock price for Hap Seng Consolidation Berhad. The maximum value of stock price is MYR 9.85 in September 2018 (33th monthly observation). The minimum value of stock price is MYR 6.66 in January 2016 (1st monthly observation).

Next, this study calculated the return rate for stock price. Fig. 6 shows return rate for stock of Hap Seng Consolidated Berhad. The average of return rate is $1.17 \%$. The standard deviation is $2.94 \%$. Meanwhile, the maximum value of return rate is $12.36 \%$ in February 2016 ( $2^{\text {nd }}$ monthly observation). The minimum value of return rate is $-4.09 \%$ in February 2018 (26 ${ }^{\text {th }}$ monthly observation).

Then, this study performed normality using graphical and numerical statistical test. Fig. 7 shows normality distribution plot of return rate for stock of Hap Seng Consolidated Berhad. Graphical plot shows there are five data points that are deviated from normal distribution. These data points are considered as outliers that contribute to non-normal distribution.

Therefore, this study performed Box-whisker plot analysis to detect outliers. Fig. 8 shows Box-whisker plot of return rate for Hap Seng Consolidated Berhad. Fig. 8 indicates there are five outliers $\left(2^{\text {nd }}, 12^{\text {th }}, 13^{\text {th }}, 26^{\text {th }}\right.$ and $27^{\text {th }}$ monthly observations).

Next, this study evaluated normality data distribution using Shapiro Wilk statistical test. Table II exhibits normality test of return data distribution for Hap Seng Consolidated Berhad using Shapiro Wilk statistical test. The significant value is 0.000 that is less than 0.05 significant levels. Therefore, the significant value concluded return data distribution follows non-normal distribution.

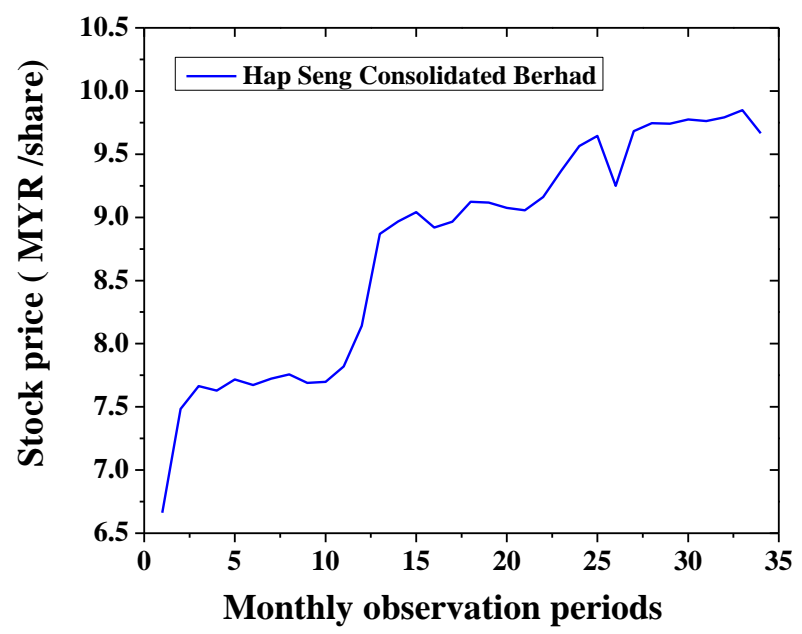

Fig. 5. Dynamic movement of stock price for Hap Seng Consolidated Berhad

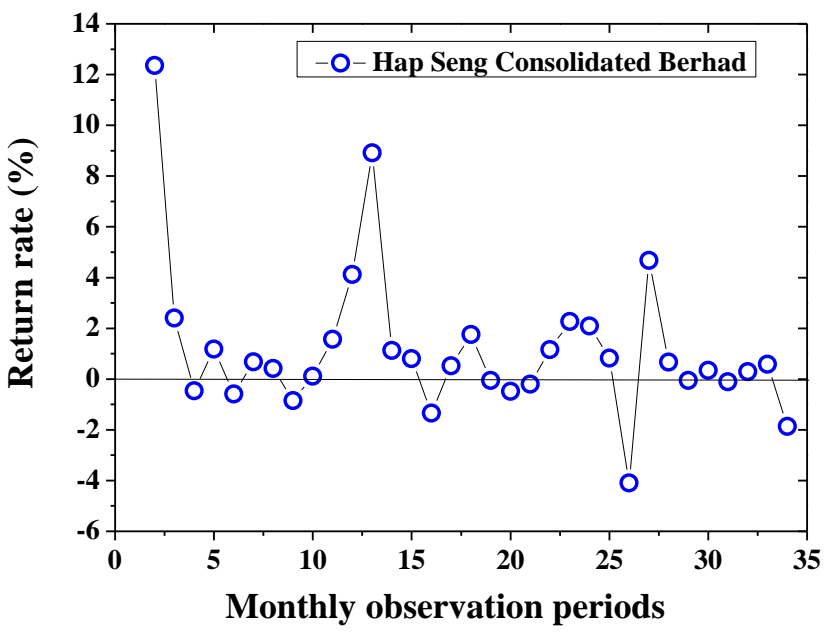

Fig. 6. Return of stock price for Hap Seng Consolidated Berhad 


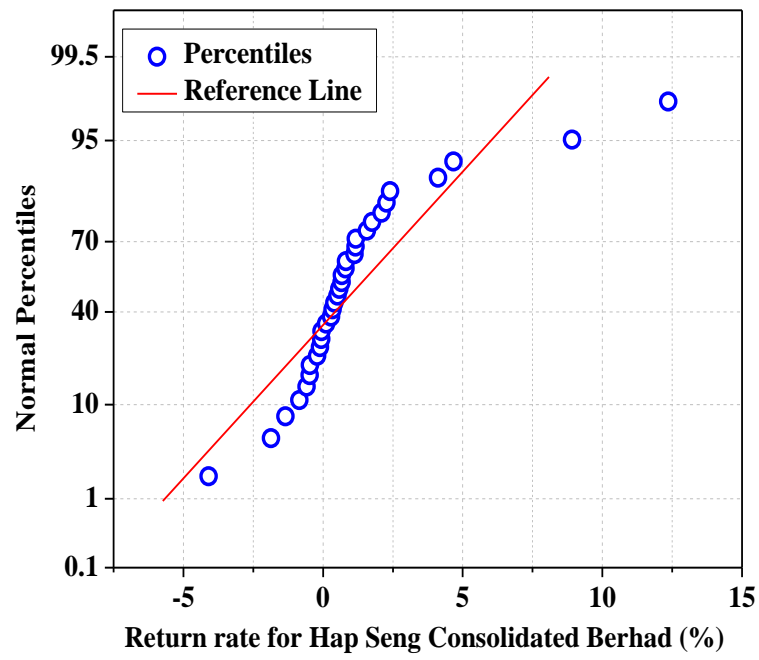

Fig. 7. Normality distribution plot of return rate for Hap Seng Consolidated Berhad

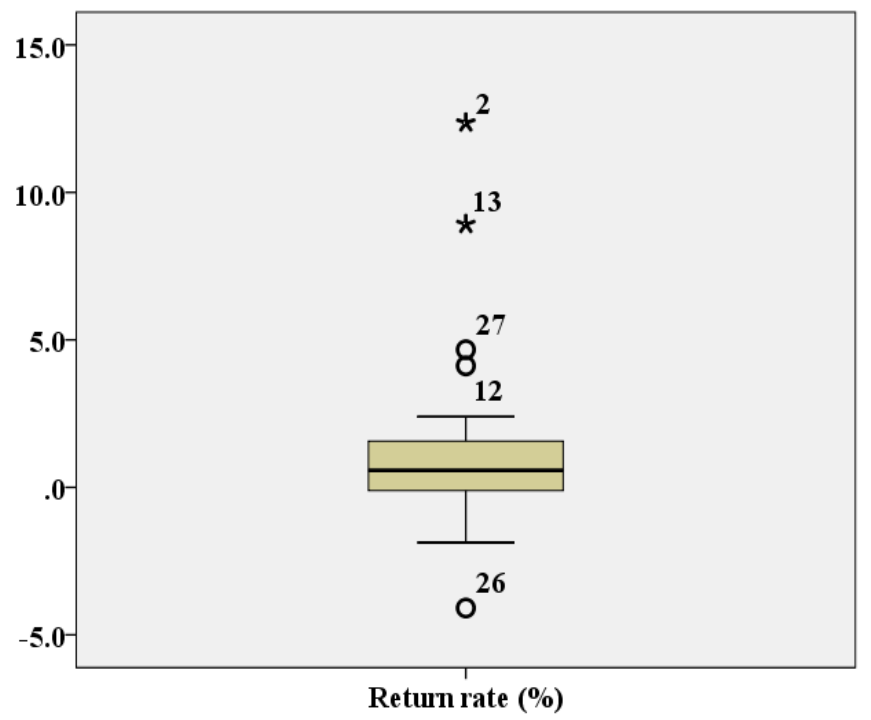

Fig. 8. Box-Whisker plot of return rate for Hap Seng Consolidated Berhad

Table II. Normality test of return data distribution for Hap Seng Consolidated Berhad

\begin{tabular}{|c|c|c|}
\hline \multicolumn{3}{|c|}{ Shapiro Wilk normality test } \\
\hline Statistics & Degree of freedom & Significant value \\
\hline 0.767 & 33 & 0.000 \\
\hline
\end{tabular}

\section{iii. Top Glove Corporation Berhad stock price analysis}

This section describes data behavior of stock price for Top Glove Corporation Berhad. Fig. 9 shows the dynamic movement of stock price for Top Glove Corporation Berhad. The maximum value of stock price is MYR 5.62 in June 2018 $\left(30^{\text {th }}\right.$ monthly observation). The minimum value of stock price is MYR 2.19 in August 2016 ( $8^{\text {th }}$ monthly observation).

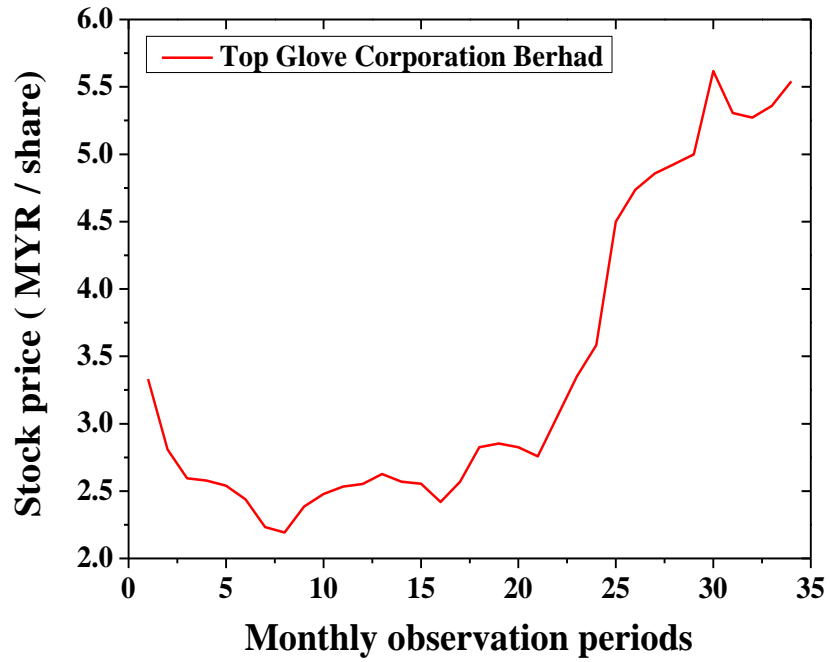

Fig. 9. Dynamic movement of stock price for Top Glove Corporation Berhad

Next, this study calculated the return rate for stock price. Fig. 10 shows return rate for stock of Top Glove Corporation Berhad. The average of return rate is $1.80 \%$. The standard deviation is $7.35 \%$. Meanwhile, the minimum value of return rate is $-15.73 \%$ in February 2016 ( $2^{\text {nd }}$ monthly observation). The maximum value of return rate is $25.58 \%$ in January 2018 ( $25^{\text {th }}$ monthly observation).

Then, this study performed normality using graphical and numerical statistical test. Fig. 11 shows normality distribution plot of return rate for stock of Top Glove Corporation Berhad. Graphical plot shows there are two data points that are deviated from normal distribution. These data points are considered as outliers that contribute to non-normal distribution.

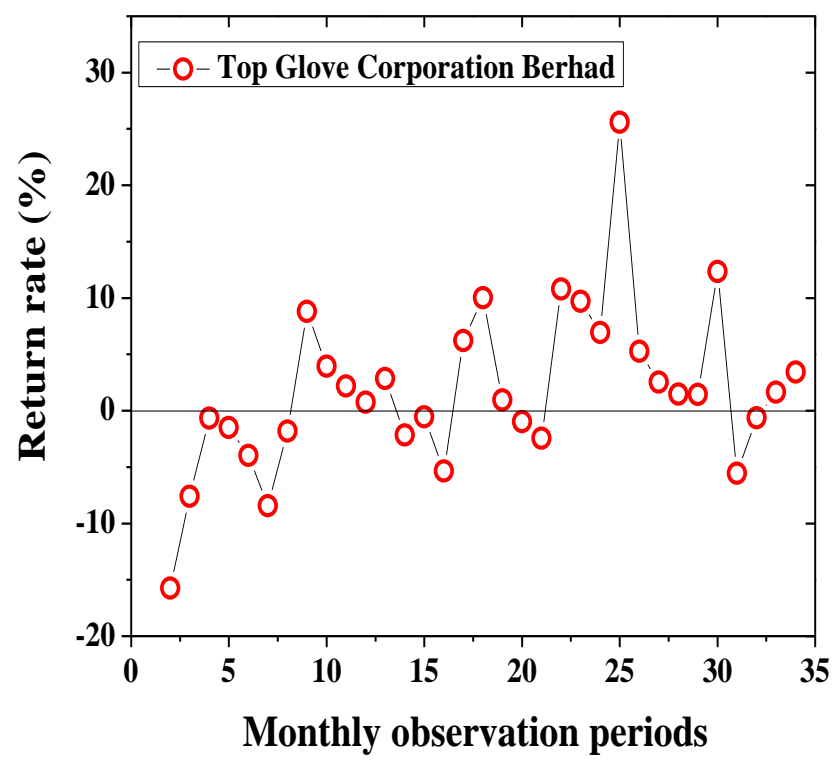

Fig. 10. Return of stock price for Top Glove Corporation Berhad 


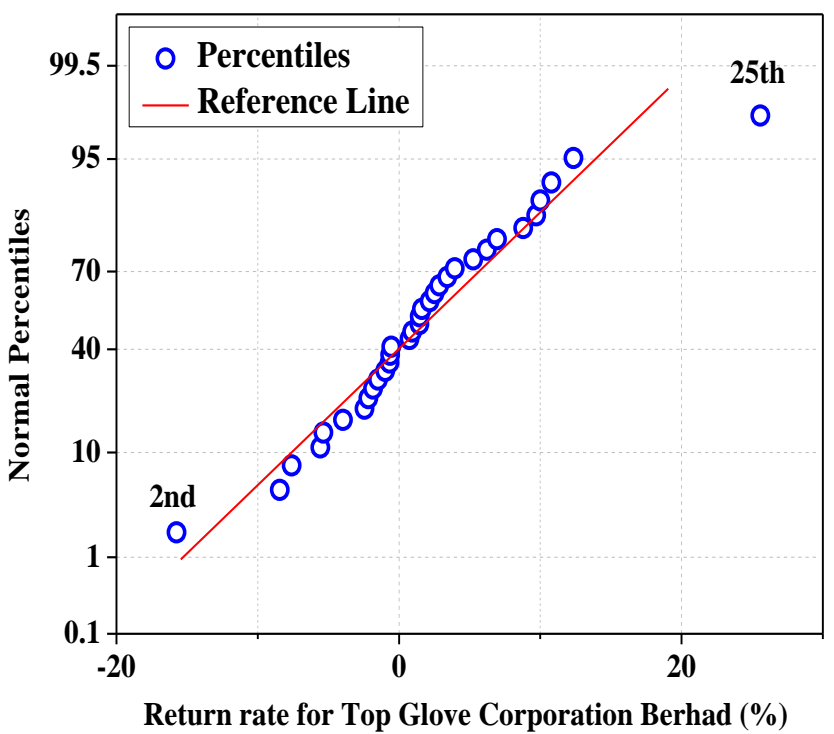

Fig. 11. Normality distribution plot of return rate for Top Glove Corporation Berhad

Therefore, this study performed Box-whisker plot analysis to detect outliers. Fig. 12 shows Box-whisker plot of return rate for Top Glove Corporation Berhad. Fig. 12 indicates there are two outliers ( $2^{\text {nd }}$ and $25^{\text {th }}$ monthly observation).

Next, this study evaluated normality data distribution using Shapiro Wilk statistical test. Table III exhibits normality test of return data distribution for Hap Seng Consolidated Berhad using Shapiro Wilk statistical test. The significant value is 0.109 that is larger than 0.05 significant levels. Therefore, the significant value concluded return data distribution follows normal distribution. The outliers exist in the data distribution are considered as good outliers that contributed to normality characteristics.

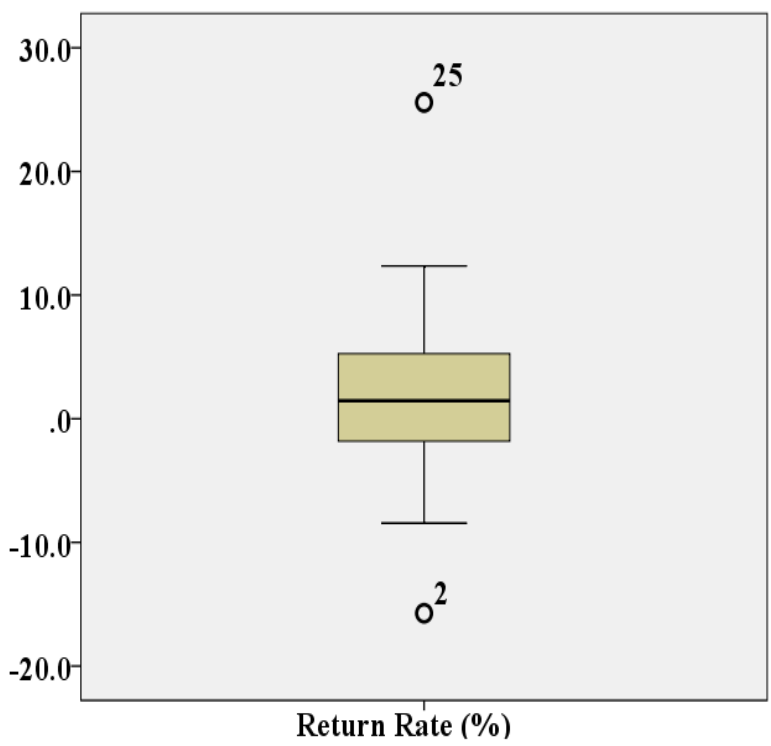

Fig. 12. Box-Whisker plot of return rate for Top Glove Corporation Berhad
Table III. Normality test of return data distribution for Top Glove Corporation Berhad

\begin{tabular}{|c|c|c|}
\hline \multicolumn{3}{|c|}{ Shapiro Wilk normality test } \\
\hline Statistics & Degree of freedom & Significant value \\
\hline 0.947 & 33 & 0.109 \\
\hline
\end{tabular}

\section{B. Pearson correlation diagnostics}

This section describes correlation association among three variables namely return rate for stock prices of Malayan Banking Berhad, Hap Seng Consolidated Berhad and Top Glove Corporation Berhad. The correlation coefficients are used in statistics to measure how strong a relationship is between two variables.

\section{i. Correlation analysis between Malayan Banking Berhad and Hap Seng Consolidated Berhad.}

Fig. 13 shows the data distribution to evaluate the correlation between return rate of stock price between Malayan Banking Berhad and Hap Seng Consolidated Berhad. Fig. 13 shows the linear fit line that can be represented using Equation (14).

$y=0.228 x+1.067$

Where, $y$ is return rate for stock price of Hap seng Consolidated Berhad, and $x$ is return rate for stock price of Malayan Banking Berhad.

Equation (14) indicates for one percentage increase in return rate for Malayan Banking Berhad, it will contributes to 0.228 percentages increase in return rate for stock price of Hap Seng Consolidated Berhad.

Next, Table IV shows the result of Pearson correlation statistical analysis between two variables. Table IV shows the correlation value is 0.259 that indicates there is weak positive association between two types of stock price return (Hap Seng and Malayan Banking). The significant value is 0.146 that is larger than 0.05 . Therefore, the correlation between these two variables is significant with weak positive correlation $(r=0.259, n=33, p=0.146)$.

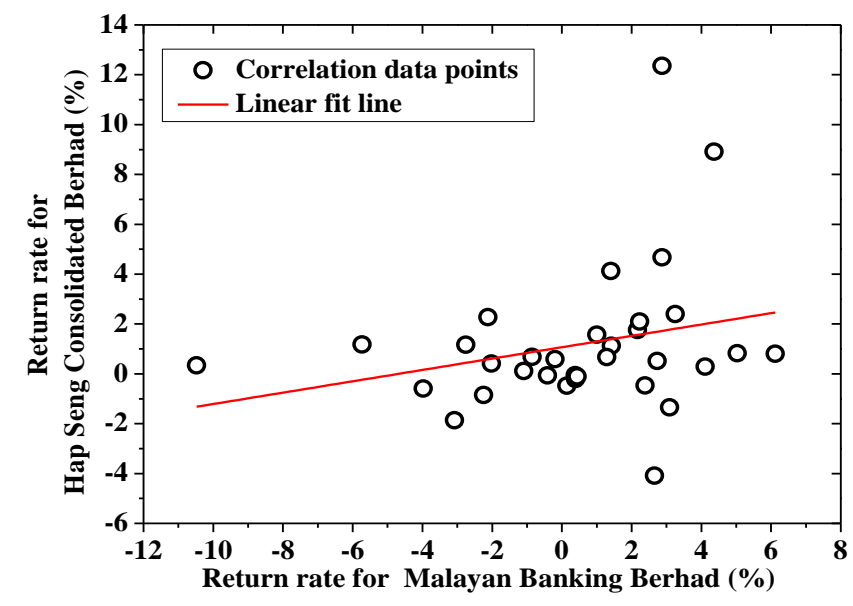

Fig. 13. Data distribution for correlation between return rate of Malayan Banking and Hap Seng Consolidated Berhad 
Table IV. Statistical test of correlation between two types of stock price return (Hap Seng and Malayan Banking)

\begin{tabular}{|c|c|c|}
\hline \multicolumn{3}{|c|}{ Hypothesis testing for bivariate correlation test } \\
\hline $\begin{array}{c}\text { Coefficien } \\
\mathbf{t}\end{array}$ & Degree of freedom & Significant value \\
\hline 0.259 & 33 & 0.146 \\
\hline
\end{tabular}

ii. Correlation analysis between Malayan Banking Berhad and Top Glove Corporation Berhad.

Fig. 14 shows the data distribution to evaluate the correlation between return rate of stock price between Malayan Banking Berhad and Top Glove Corporation Berhad. Fig. 14 shows the linear fit line that can be represented using Equation (15).

$y=-0.241 x+1.918$

Where, $y$ is return rate for stock price of Top Glove Corporation Berhad, and $x$ is return rate for stock price of Malayan Banking Berhad.

Equation (15) indicates for one percentage increase in return rate for Malayan Banking Berhad, it contributes to 0.241 percentages decrease in return rate for stock price of Top Glove Corporation Berhad.

Next, Table $\mathrm{V}$ shows the result of Pearson correlation statistical analysis between two variables. Table V shows the correlation value is -0.110 that indicates there is weak negative association between two types of stock price return (Malayan Banking and Top Glove). The significant value is 0.542 that is larger than 0.05 . Therefore, the correlation between these two variables is significant with weak negative correlation ( $r=-0.110, n=33, p=0.542)$.

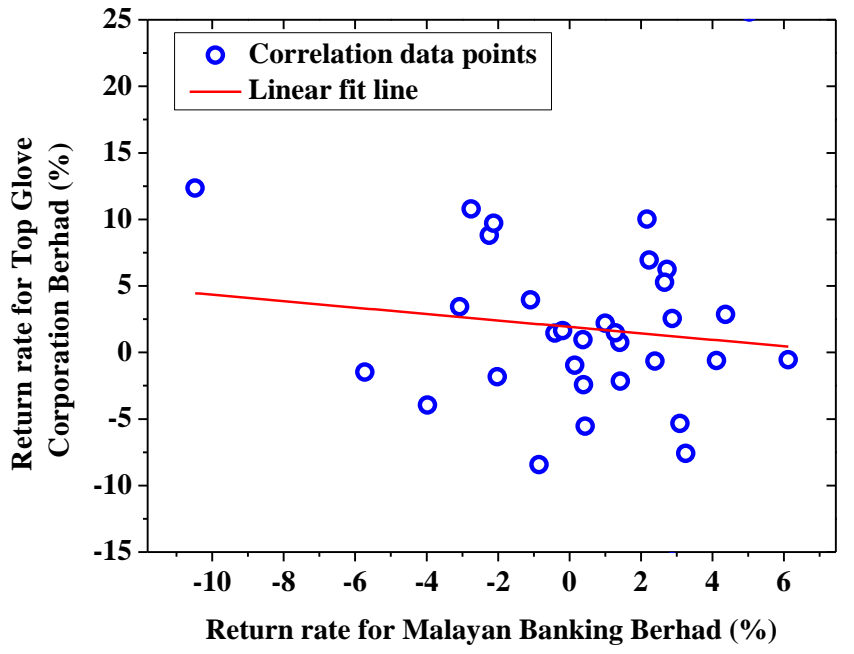

Fig. 14. Data distribution for correlation between return rate of Malayan Banking and Top Glove Corporation Berhad

Table V. Statistical test of correlation between two types of stock price return (Malayan Banking and Top Glove)

\begin{tabular}{|c|c|c|}
\hline \multicolumn{3}{|c|}{ Hypothesis testing for bivariate correlation test } \\
\hline $\begin{array}{c}\text { Coefficien } \\
t\end{array}$ & Degree of freedom & Significant value \\
\hline-0.110 & 33 & 0.542 \\
\hline
\end{tabular}

Retrieval Number: F10230986S319/2019@BEIESP

\section{iii. Correlation analysis between Hap Seng Consolidated Berhad and Top Glove Corporation Berhad.}

Fig. 15 shows the data distribution to evaluate the correlation between return rate of stock price between Hap Seng Consolidated Berhad and Top Glove Corporation Berhad. Fig. 15 shows the linear fit line that can be represented using Equation (16).

$y=-0.637 x+2.552$

Where, $y$ is return rate for stock price of Top Glove Corporation Berhad, and $x$ is return rate for stock price of Hap Seng Consolidated Berhad.

Equation (16) indicates for one percentage increase in return rate for Hap Seng Consolidated Berhad, it contributes to 0.637 percentages decrease in return rate for stock price of Top Glove Corporation Berhad.

Next, Table VI shows result of Pearson correlation statistical analysis between two variables. Table VI shows the correlation value is -0.255 that indicates there is weak negative association between two types of stock price return (Hap Seng Consolidated Berhadand Top Glove Corporation Berhad). The significant value is 0.152 that is larger than 0.05 . Therefore, the correlation between these two variables is significant with weak negative correlation $(r=-0.255$, $n=33, p=0.152$ )

\section{Modern Portfolio Theory using diversification approach to reduce investment}

Modern Portfolio Theory is an investment theory based on the idea that risk-averse investors can construct portfolios to optimize or maximize expected return based on a given level of market risk, emphasizing that risk is an inherent part of higher reward. An optimal portfolio is investment portfolio that offering the maximum possible expected return for a given level of risk. The risk of investment can be lowered with constructing portfolio with different financial assets.

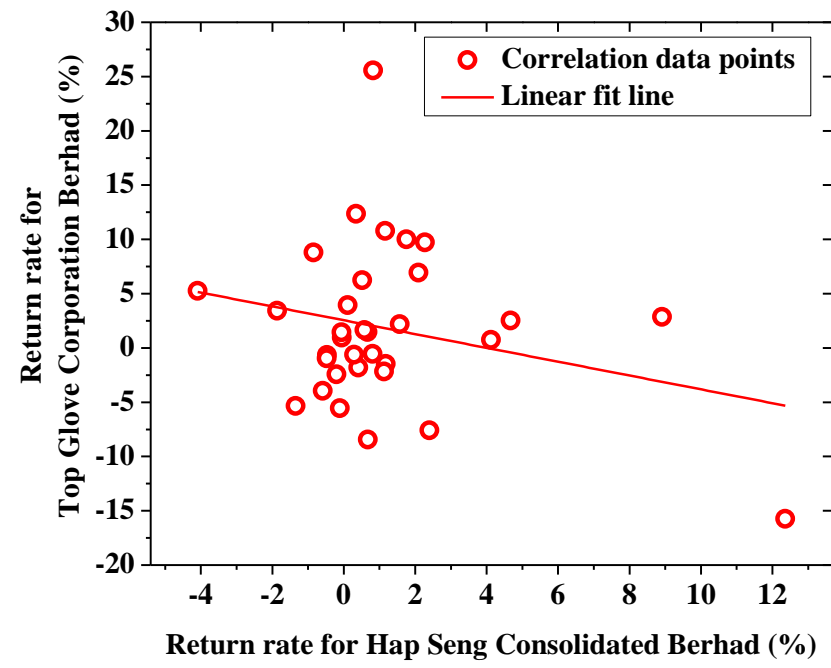

Fig. 15. Data distribution for correlation between return rate of Hap Seng and Top Glove Corporation Berhad 
Table VI. Statistical test of correlation between two types of stock price return (Hap Seng and Top Glove)

Hypothesis testing for bivariate correlation test

\begin{tabular}{|c|c|c|}
\hline $\begin{array}{c}\text { Coefficien } \\
\mathbf{t}\end{array}$ & Degree of freedom & Significant value \\
\hline-0.255 & 33 & 0.152 \\
\hline
\end{tabular}

In this study, the diversification of the investment portfolio is constructed using three different types of stock prices namely Malayan Banking Berhad, Hap Seng Consolidated Berhad and Top Glove Corporation Berhad.

Fig. 16 shows the portfolio risk (standard deviation) and expected return for portfolio investment consists of three financial assets. There are three combination of calculation involved in this study. The first combination (combination A) is developed from two stock returns namely Hap Seng Consolidated Berhad and Top Glove Corporation Berhad. In Fig. 16, this combination is represented by black dot. The second combination (combination B) is developed from two stock returns namely Malayan Banking Berhad (Maybank) and Top Glove Corporation Berhad. In Fig. 16, the combination is represented by red dots. Next, the third combination (combination C) is developed from two stock returns namely Malayan Banking Berhad (Maybank) and Hap Seng Consolidated Berhad. In Fig. 16, the combination is represented by blue dots.

Combination A shows the minimum value of portfolio risk is $2.437 \%$ with expected portfolio return is $1.300 \%$. This point indicates the allocation of investment fund ratio is $80 \%$ for Hap Seng Consolidated Berhad and $20 \%$ for Top Glove Corporation Berhad. Next, combination B shows the minimum value of portfolio risk is $2.903 \%$ with expected portfolio return is $0.736 \%$. This point exhibits the allocation of investment fund ratio is $80 \%$ for Malayan Banking Berhad and $20 \%$ for Top Glove Corporation Berhad. Meanwhile, combination $\mathrm{C}$ shows the minimum value of portfolio risk is $2.474 \%$ with expected return is $0.892 \%$. This point shows the allocation of investment fund ratio is 40 $\%$ for Malayan Banking berhad and $60 \%$ for Hap Seng Consolidated Berhad.

Fig. 16 indicates the combination A shows higher expected return than combination $\mathrm{B}$ and $\mathrm{C}$. The underlying reason is because Hap Seng and Top Glove contribute higher return compared to Maybank. Therefore, combination of Hap Seng and Top Glove contributes more return for similar portfolio risk value.

Then, in developing robust solution, this study performed calculations with more combination to develop the solutions space for three combinations of financial assets. Fig. 17 shows the solutions space for different combinations three financial assets with different weightages of fund allocation.

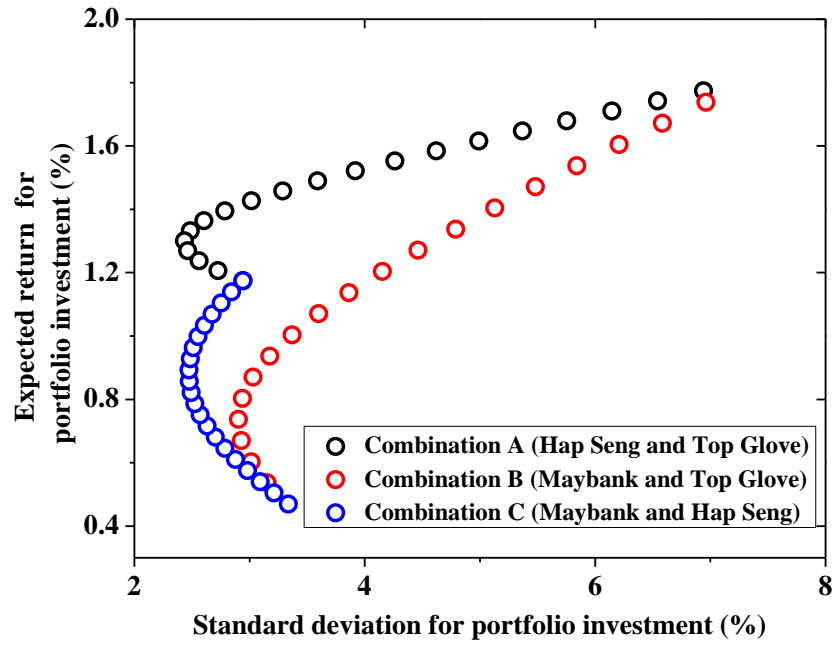

Fig. 16. Correlation between portfolio expected return and portfolio risk (standard deviation) for three combinations of financial assets

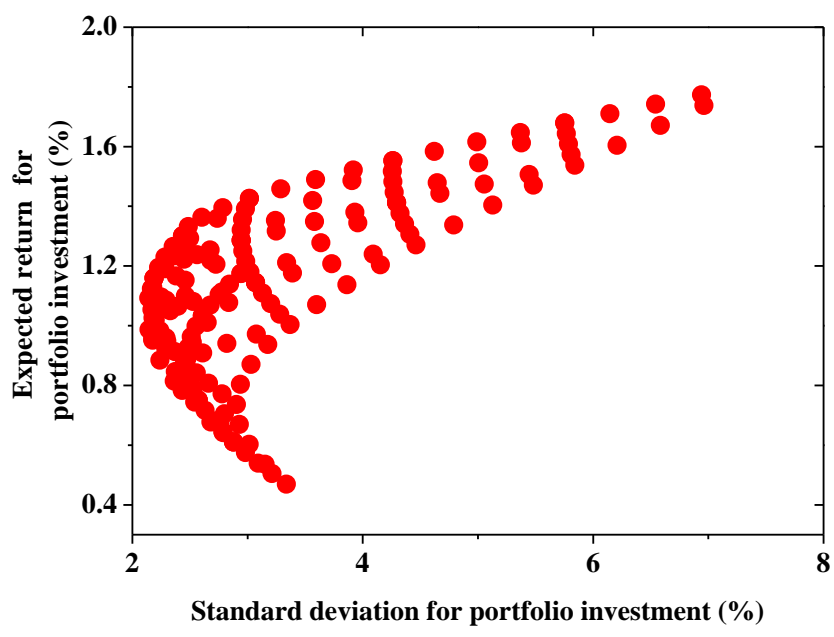

Fig. 17. Solutions space for different combinations three financial assets with different weightage of fund allocation

\section{Genetic algorithm approach to estimating lower portfolio risk in Modern Portfolio Theory}

In analyzing the association between portfolio risk and expected return, the determination of efficient value become more complicated as the number of financial assets is increasing. Therefore, an application of optimization is a one of the method to develop more robust value of efficient frontier to validate the portfolio risk and expected return of portfolio investment.

This study implemented genetic algorithm to improve the efficiency of modern portfolio theory for solving of minimum portfolio risk. This algorithm reflects the process of natural selection where the fittest individuals are selected for reproduction in order to produce offspring of the next generation.

The objective function for portfolio risk is represented by portfolio risk in Equation (17). 


$$
\sigma_{p}=\left(\begin{array}{l}
w_{A}^{2} \sigma_{A}^{2}+w_{B}^{2} \sigma_{B}^{2}+w_{C}^{2} \sigma_{C}^{2} \\
+2 w_{A} w_{B} \sigma_{A} \sigma_{B} \rho_{A B} \\
+2 w_{A} w_{C} \sigma_{A} \sigma_{C} \rho_{A C} \\
+2 w_{B} w_{C} \sigma_{B} \sigma_{C} \rho_{B C}
\end{array}\right)^{\frac{1}{2}}
$$

Parameters in Equation (17) are described as below: $w_{A}$ : Weightage of Malayan Banking Berhad (asset A). $\sigma_{A}:$ Standard deviation for return rate of asset A.

$w_{B}$ : Weightage of Hap Seng Consolidated Berhad (asset B).

$\sigma_{B}$ : Standard deviation for return rate of asset B.

$w_{C}$ : Weightage of Top Glove Corporation Berhad (asset C).

$\sigma_{C}$ : Standard deviation for return rate of asset C.

$\rho_{A B}$ : Correlation coefficient between asset A and B.

$\rho_{A C}$ : Correlation coefficient between asset $\mathrm{A}$ and $\mathrm{C}$.

$\rho_{B C}$ : Correlation coefficient between asset B and C.

Therefore, Equation (17) can be represented as Equation (18) after considering the values of data in this study.

$$
\sigma_{p}=\left(\begin{array}{l}
11.15 w_{A}^{2}+8.66 w_{B}^{2}+53.96 w_{C}^{2} \\
+2 w_{A} w_{B}(3.34)(2.94)(0.2584) \\
+2 w_{A} w_{C}(3.34)(7.35)(-0.1099) \\
+2 w_{B} w_{C}(2.94)(7.35)(-0.2551)
\end{array}\right)^{\frac{1}{2}}
$$

Next, the linear equality is set for weightage ratio between investment of asset A, B and C. Therefore, linear equality is represented by using Equation (19). The total of investment in all of three assets is represented as 1 .

$$
w_{A}+w_{B}+w_{C}=1
$$

Then, the lower bound and upper bound is set for weightage ratio between investments of asset $\mathrm{A}, \mathrm{B}$ and $\mathrm{C}$. Lower bound of assets $\left(w_{A}, w_{B}, w_{C}\right)$ is set as $(0,0,0)$. Then, upper bound of assets is set as $(1,1,1)$.This setting indicates the weightage of investment ratio for each asset can take value from 0 until 1.

Next, the genetic algorithm uses three main types of rules at each step to create the next generation from the current population.

(i)Selection rules select the individuals, called parents that contribute to the population at the next generation.

(ii)Crossover rules combine two parents to form children for the next generation.

(iii)Mutation rules apply random changes to individual parents to form children.

The selection rule is using stochastic uniform. The setting for elite parents is two. Then, crossover ratio is set to 80 percentages and mutation ratio is 20 percentages.

The optimum value of $\left(w_{A}, w_{B}, w_{C}\right)$ is shown in Table VII. The optimum value of minimization for fitness function shows the lower portfolio risk of investment weightage $\left(w_{A}, w_{B}, w_{C}\right)$. The initial population is set as 4000 chromosomes (combinations of $w_{A}, w_{B}, w_{C}$ ).

Table VII shows the value for investment weightage of asset A, asset B and asset C. The genetic algorithm calculation performed for ten times. The average value of $w_{A}$ is $0.3224, w_{B}$ is 0.5237 and $w_{C}$ is 0.1530 . The average value minimum portfolio risk in objective function is 2.122118 .

Fig. 18 shows mean fitness analysis for solutions space of portfolio weightage using genetic algorithm. The red dot represents best fitness of optimal solution. Next, the blue circle represents mean fitness of optimal solutions. The optimal solution for best fitness is 2.1221. This value indicates the lowest portfolio risk that can be attained using genetic algorithm. Meanwhile, mean fitness of solution is 2.1362. This value indicates mean of minimum portfolio risk among populations of solution. Fig. 18 shows starting from generation of 24 , the difference between best fitness solutions with mean fitness of population close to zero. Fig. 19 shows the average distance between individuals in genetic algorithm to solve for minimum portfolio risk.

Table VII. Optimum value for investment weightage using genetic algorithm

\begin{tabular}{|c|c|c|c|c|}
\hline Test & $w_{A}$ & $w_{B}$ & $w_{C}$ & $\begin{array}{c}\text { Fitness } \\
\text { function } \\
\text { value }\end{array}$ \\
\hline $\mathbf{1}$ & 0.3227 & 0.5231 & 0.1532 & 2.122119 \\
\hline $\mathbf{2}$ & 0.3224 & 0.5235 & 0.1531 & 2.122118 \\
\hline $\mathbf{3}$ & 0.3212 & 0.5244 & 0.1534 & 2.122119 \\
\hline $\mathbf{4}$ & 0.3224 & 0.5252 & 0.1514 & 2.122118 \\
\hline $\mathbf{5}$ & 0.3226 & 0.5233 & 0.1531 & 2.122119 \\
\hline $\mathbf{6}$ & 0.3225 & 0.5234 & 0.1531 & 2.122118 \\
\hline $\mathbf{7}$ & 0.3222 & 0.5236 & 0.1532 & 2.122118 \\
\hline $\mathbf{8}$ & 0.3230 & 0.5231 & 0.1530 & 2.122119 \\
\hline $\mathbf{9}$ & 0.3222 & 0.5237 & 0.1531 & 2.122118 \\
\hline $\mathbf{1 0}$ & 0.3224 & 0.5234 & 0.1532 & 2.122118 \\
\hline Average & $\mathbf{0 . 3 2 2 4}$ & $\mathbf{0 . 5 2 3 7}$ & $\mathbf{0 . 1 5 3 0}$ & $\mathbf{2 . 1 2 2 1 1 8}$ \\
\hline
\end{tabular}




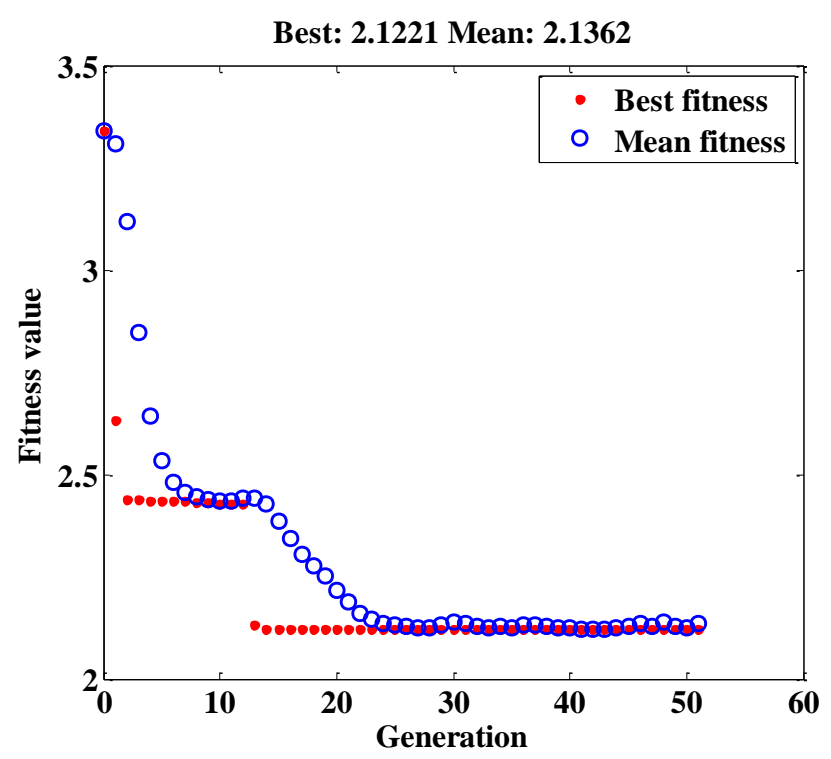

Fig. 18. Mean fitness analysis for solutions space of portfolio weightage using genetic algorithm

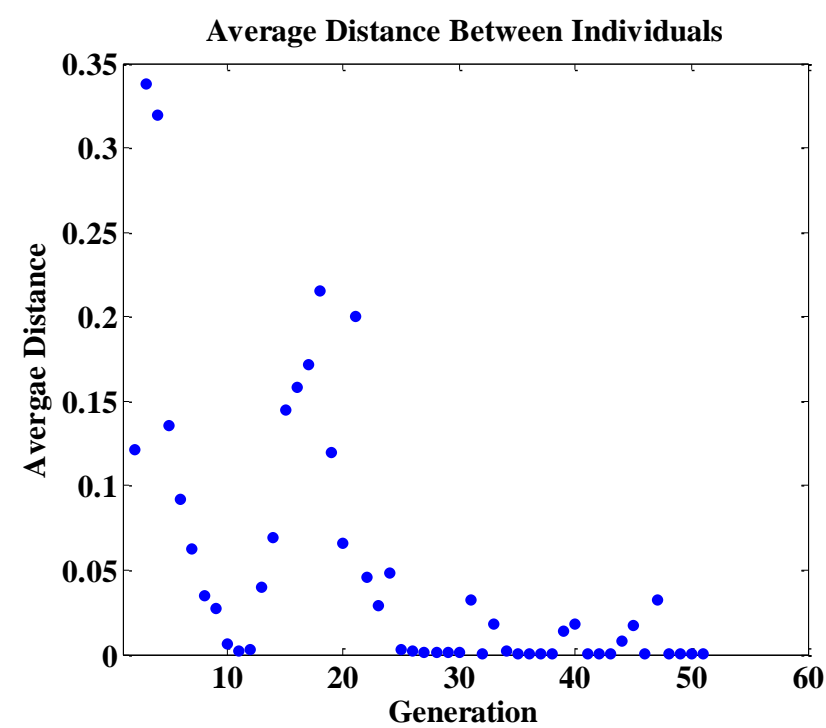

Fig. 19. Average distance between individual for solutions space of portfolio weightage using genetic algorithm

\section{CONCLUSIONS}

Main objective of this study is to develop efficient frontier for portfolio investment to achieve lower risk. In addition, genetic algorithm implemented to produce robust result to achieve lower risk of investment for portfolio. Main findings of this study are:

(a) This study selected three stocks from Malaysia Stock

Exchange namely Malayan Banking Berhad, Hap Seng Consolidated Berhad and Top Glove Corporation Berhad. Data of stock prices are collected from Thomson Reuters Datastream. The analysis period is from 1st January 2016 until 31st October 2017. This study calculated the monthly data for analysis procedure. There are 34 monthly observations for evaluating the investment portfolio risk.

(b) The Pearson correlation coefficient is used in statistics to measure how strong a relationship is between two variables. In this study, the correlation between these two variables (Hap Seng Berhad and Malayan Banking Berhad) is significant with weak positive correlation ( $r=0.259, n=33, p=0.146$ ). In addition, the correlation between two stocks (Top Glove and Malayan Banking) is significant with weak negative correlation $(r=-0.110$, $n=33, p=0.542$ ). Meanwhile, the correlation between two stocks (Top Glove and Hap Seng) is significant with weak negative correlation ( $r=-0.255, n=33, p=0.152$ ).

(c) In evaluating investment risk, this study implemented Markowitz theory. Result indicates combination of Hap Seng and Top Glove contributes more return for similar portfolio risk value compared to other combinations. The minimum value of portfolio risk is $2.437 \%$ with expected portfolio return is $1.300 \%$. This point indicates the allocation of investment fund ratio is $80 \%$ for Hap Seng and $20 \%$ for Top Glove.

(d) This study implemented genetic algorithm to improve accuracy of Modern Portfolio Theory. The genetic algorithm calculation performed for ten times. The average value of $w_{A}$ is $0.3224, w_{B}$ is 0.5237 and $w_{C}$ is 0.1530 . The average value of minimum portfolio risk in objective function is 2.122118 . This value indicates with implementation of genetic algorithm optimization, robust result can be achieved.

\section{SIGNIFICANT OF THIS STUDY}

This study provides better accuracy of evaluating investment risk of diversification portfolio. Therefore, this study helps investors to attain higher return with lower risk for a specific investment portfolio.

\section{FURTHER STUDY}

This study can be extending to analyze factors that contribute to volatility of return for stock prices in Malaysia Stock Exchange. In the same time, this study also can implement particle swarm optimization with comparison to genetic algorithm to attain better accuracy of risk minimization.

\section{REFERENCES}

1. Markowitz, H. (1952). Portfolio Selection, Journal of Finance, vol. 7, no. 1, pp. 77-91

2. Abu Bakar, N. and Rosbi, S. (2018). Evaluation of Risk Reduction for Portfolio in Islamic Investment Using Modern Portfolio Theory International Journal of Advanced Engineering Research and Science, vol. 5, no. 11, pp. 27-34.

3. Abu Bakar, N. and Rosbi, S. (2018). Efficient frontier analysis for portfolio investment in Malaysia stock market. Science International (Lahore), vol. 30, no. 5, pp. 723-729.

4. Abu Bakar, N and Rosbi, S. (2019) Volatility Diagnostics for Stock Price of Sharia-Compliant Companies listed in Malaysia Composite Index. International Journal of Advanced Engineering Research, Management and Science, vol. 5, no. 2, pp. 116-121.

5. Kazan, H. and Uludag, K. (2014). Credit Portfolio Selection According to Sectors in Risky Environments: Markowitz Practice. Asian Economic and Financial Review, vol. 4, no. 9, pp. 1208-121.

6. Abu Bakar, N. and Rosbi, S. (2018). Diversification diagnostics for portfolio investment using combination of cryptocurrency and stock price. International Journal of Advanced Research, vol. 6, no. 10, pp 1528-1539. 
7. Ho, H/D, Hui, E.C.M. and Su, H. (2010). Examining fuzzy tactical asset allocation (FTAA) as an alternative to modern portfolio theory (MPT) asset allocation for international and direct real estate investment. Journal of Financial Management of Property and Construction, vol. 15, no. 1 , pp. 71-94.

8. Azizan, N.A. and Sorooshian, S. (2014). Stock Market performance and modern portfolio theory: Case on Malaysian stock market and Asian Indices. WSEAS Transactions on Business and Economics, vol. 11, pp. 303-313.

9. Fabozzi, F.J., Gupta, F. and Markowitz, H.M. (2002). The Legacy of Modern Portfolio Theory. The Journal of Investing, vol. 11, no. 3, pp. 7-22.

10. Solimanpur, M., Mansourfar, G., Ghayour, F. (2015). Optimum portfolio selection using a hybrid genetic algorithm and analytic hierarchy process. Studies in Economics and Finance, vol. 32, no. 3, pp. 379-394.

11. Ehrgott, M., Klamroth, K. and Schwehm, C. (2004). An MCDM approach to portfolio optimization. European Journal of Operational Research, vol. 155 , no. 3, pp. 752-770.

12. Abu Bakar, N. and Rosbi, S. (2019) Monte Carlo Simulation for Data Volatility Analysis of Stock Prices in Islamic Finance for Malaysia Composite Index. International Journal of Advanced Engineering Research and Science, vol. 6, no. 3, pp. 6-12.

13. Adkins, L. C., Gade, M. N. (2012). Monte Carlo Experiments Using Stata: A Primer with Examples, in Dek Terrell, Daniel Millimet (ed.) $30^{\text {th }}$ Anniversary Edition (Advances in Econometrics, Volume 30) Emerald Group Publishing Limited, pp. 429 - 477.

14. Esfahanipour, A. and Tayari, M. (2014). A genetic network programming model for portfolio optimization by generating risk-adjusted trading rules. 10th International Industrial Engineering Conference, pp. 1-7.

15. He, F.B. and Chang, J. (2014). Combined forecasting of regional logistics demand optimized by genetic algorithm. Grey Systems: Theory and Application, vol. 4, no. 2, pp. 221-231.

16. Rabbani, M., Pourreza, P., Asl, H.F. and Nouri, N. (2018). A hybrid genetic algorithm for multi-depot vehicle routing problem with considering time window repair and pickup. Journal of Modelling in Management, vol. 13, no. 3, pp. 698-717.

17. Taheri, A., Davoodi, M. and Setayeshi, S. (2012). Investigation of electron mobility in GaAs- based devices using genetic algorithm. The International Journal for Computation and Mathematics in Electrical and Electronic Engineering, vol. 31, no. 2, pp. 604-618.

18. Sakha, M.S. and Shaker, H.R. (2017). Optimal sensors and actuators placement for large-scale unstable systems via restricted genetic algorithm. Engineering Computations, vol. 34, no. 8, pp. 2582-2597.

19. Yang, X., Yu, L., and Zhao, X.S. (2017). Optimization of the reefed parachute using genetic algorithm. Engineering Computations, vol. 34 no. 6, pp. 1923-1938

20. Farahat, S., Javadpour, S.M., Hamidi, H.E. and Kadivar, E. (2015). Optimization of a supersonic wind tunnel diffuser using genetic algorithm. Engineering Computations, vol. 32, no. 6, pp. 1691-1707.

21. Yao, Y., Wang, Y., Xing, L. and Xu, H. (2015). An optimization method of technological processes to complex products using knowledge-based genetic algorithm. Journal of Knowledge Management, vol. 19, no. 1, pp. 82-94.

22. Lin, D., Shen, B., Liu, Y., Alsaadi, F.E. and Alsaedi, A. (2017). Genetic algorithm-based compliant robot path planning: an improved Bi-RRT-based initialization method. Assembly Automation, vol. 37, no. 3, pp. 261-270.

23. Rodríguez, F.F., Martel, C.G. and Rivero, S.S. (2001). Optimisation of technical rules by genetic algorithms: Evidence from the Madrid stock market. Applied Financial Economics, vol. 15, no. 11, pp. 773-775.

24. Holland, J., Adaptation in natural and artificial systems. University of Michigan Press, Michigan, 1975.

25. Sharma, B., Thulasiram, R.K. and Thulasiraman, P. (2015). Computing value-at-risk using genetic algorithm. The Journal of Risk Finance, vol. 16 , no. 2, pp. $170-189$.

26. Mangram, M.E. (2013). A simplified perspective of the Markowitz portfolio theory. Global Journal of Business Research, vol. 7, no. 1, pp. 59-70.

27. Ou, J. (2005). Theory of portfolio and risk based on incremental entropy. The Journal of Risk Finance, vol. 6, no. 1, pp. 31-39.

28. Giannotti, C., Mattarocci, G. and Spinelli, L. (2011). The role of portfolio diversification in the hotel industry: Evidence from the Italian market. EuroMed Journal of Business, vol. 6, no. 1, pp. 24-45.

29. Abu Bakar, N. Rosbi, S. and Uzaki, K. (2019). Robust Long Term Performance Analysis for Initial Public Offerings Using Market Adjusted Buy and Hold Returns (MABHR) Model, The International Journal of Engineering and Science, vol. 8, no. 1, pp. 8-15.

\section{AUTHORs ProfiLe}

Dr. Nashirah Abu Bakar is currently a senior lecturer of Islamic Business School (IBS) College of Business, Universiti Utara Malaysia (UUM). She obtained $\mathrm{PhD}$ degree from Oita University, Japan in 2015. She has done extensive research in the areas of Islamic Investment, Islamic Shares Price, Islamic Financial Statistic and Islamic Financial Engineering and, to date has published more than 40 of her work in academic journals and has presented over 20 papers in both local and international conferences. In addition, her scholarly contribution could also be observed in her reviewing manuscripts for five international refereed journals.

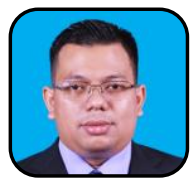

Dr. Sofian Rosbi is senior lecturer in Universiti Malaysia Perlis in Malaysia. His research interest is mathematical modelling, time series and optimization. He obtained $\mathrm{PhD}$ degree from Oita University, Japan in 2015. 